\title{
José Martí: sua Visão de Progresso e o Materialismo Histórico
}

\author{
Fabio Luis Barbosa dos Santos ${ }^{(*)}$
}

Resumo: Neste trabalho, procederemos a uma apreciação crítica da visão de progresso de José Martí (1853- 1895) do ponto de vista do materialismo histórico. Com esta finalidade, o texto realizará o seguinte movimento: após a exposição das linhas mestras da visão de progresso martiana, buscaremos investigar primeiramente o alcance e, a seguir, o limite crítico da sua chave interpretativa. Depois, relacionaremos suas premissas ideológicas com a leitura que faz sobre: a) Marx; b) o socialismo; c) um projeto nacional para Cuba. Encerramos o texto com algumas observações sobre o seu pensamento que dialogam com os dilemas históricos do continente.

Palavras-chave: José Martí; pensamento latino-americano; revolução democrática-nacional; materialismo histórico.

Abstract: This article undertakes a critical appreciation of José Martí's (1853- 1895) view of progress from the standpoint of the historical materialism. Aiming at this purpose, the argument is presented according to the following steps: after a general exposition of the main lines of Martí's view of progress, we attempt to analyze both the extent and the limits of his social criticism. After that, we relate those ideological premises with his approach of a) Marx; b) socialism; c) and a national project for Cuba. The article ends with a few notes relating his thought to the historical dilemmas of Latin America.

Keywords: José Martí; Latin American thought; national democratic revolution; historical materialism.

(*) Doutorando em História Econômica pela FFLCH - USP. E-mail: < faboroso@gmail.com>.

Recebido em 22.3.2010 e aceito em 25.4.2011. 


\section{INTRODUÇão}

Neste trabalho, procederemos a uma apreciação crítica da visão de progresso martiana do ponto de vista do materialismo histórico. Com esta finalidade, o texto realizará o seguinte movimento: depois da exposição das linhas mestras da visão de progresso segundo Martí, buscaremos investigar primeiramente o alcance e, a seguir, o limite crítico, da sua chave interpretativa para, em seguida, realizarmos algumas observações relacionando o seu pensamento aos dilemas históricos do continente.

\section{VISÃO DE PROGRESSO}

A visão de progresso martiana cristaliza-se no ideário de Nuestra América como um projeto civilizatório próprio, alternativo à modernidade ocidental, produto da conjunção entre a sua visão de homem consubstanciada na noção do hombre natural, e a sua visão da história angulada em torno da noção do caráter como chave da interpretação de um povo. A noção do hombre natural tem como premissa uma dimensão transcendente da existência, que deve orientar a organização social em contraste com o materialismo típico das sociedades industriais. A partir deste ângulo, Martí questiona o parâmetro civilizatório ocidental e sugere formas alternativas de construção, organização e divulgação do conhecimento, que obedeçam a outra racionalidade inclusiva do sentimento, presidida por uma lógica aditiva e não demonstrativa e cujo sentido precípuo é dado pela realização do humano fundada no amor.

Martí identifica na característica específica da formação latino-americana a potencialidade de afirmação histórica do hombre natural como ideal civilizatório ${ }^{(1)}$, visão assentada na noção do caráter como expressão ética da característica histórica de um povo. Por isso, para Martí, a valorização do autóctono é ao mesmo tempo o método político da emancipação e a via espiritual da realização humana.

Assim, na chave martiana progresso, significa criar condições históricas para a afirmação do hombre natural, o que se traduz na promoção de uma noção alternativa de modernidade orientada por princípios éticos pautados pelo amor, passível de realização por meio do projeto de Nuestra América, que tem como pressuposto a afirmação da autoctonia a partir da esfera cultural, premissa para a emancipação política e econômica. Projetada no fluxo da história universal, a causa da independência das Antilhas adquire consequências civilizatórias decisivas, porque pode brecar o expansionismo estadunidense e favorecer o equilíbrio geopolítico do mundo, viabilizando o experimento da república moral como inovação humanística.

Em outras palavras, Martí propõe um particular (a autoctonia) como via de afirmação de um universal (o homem). Nesta visão, existem nexos tangíveis entre o processo político de independência cubana e a marcha civilizatória, bem como entre a emancipação da América Latina e a libertação do homem na sua integralidade. Em suma, em Martí, a afirmação da autoctonia é a realização do humano: patria es humanidad.

(1) Caráter no sentido de característica. Ao contrário do que a palavra indica, esta noção não está alicerçada em uma suposta essência, mas, antes, remete a um processo dinâmico de revelação ou não de potencialidades históricas. Assim, em Nuestra América, é na "diferencia de orígenes, metodos y intereses entre los dos factores continentales", que radica o contraste entre as duas Américas (MARTÍ, 2000, tomo II, p. 480). 
Nesta perspectiva, o êxito da guerra nas Antilhas é duplamente estratégico: do ponto de vista da geopolítica global, é a possibilidade de minar o expansionismo estadunidense e facultar a unidade americana, ao mesmo tempo em que é a pedra fundamental de um projeto civilizatório alternativo. Ambos os vetores têm alcance mundial. Isto que significa que Martí concede papel protagonista ao continente do ponto de vista político, e estatura universal ao potencial cultural de Nuestra América, do ponto de vista humano.

Martí identifica, pois, o progresso da civilização com a afirmação do potencial histórico de Nuestra América. Esta visão está assentada na noção do caráter como chave para a interpretação histórica de um povo. Ao contrário do que a palavra indica, o caráter não está referido a uma suposta essência, mas sim a um processo de revelação ou não de potencialidades históricas. A decorrência implícita desta positivação da cultura latino-americana é um ceticismo em relação ao horizonte dos povos ocidentais. Embora a autoctonia seja a chave da afirmação histórica de povos de caráter distinto, como os Estados Unidos ou a Europa, ela não universaliza a possibilidade de realização do hombre natural: esta seria a especificidade da contribuição civilizatória americana.

Porque o outro lado da relação entre autoctonia e caráter é a compreensão que Martí tem do ódio de classes como característica dos povos ocidentais, que remete a um passado feudal. Ou seja: é uma especificidade europeia, que se reproduz nos Estados Unidos, país em que ocorre uma espécie de feudalização aguçada pela orientação materialista daquela sociedade. Nessas condições, bloqueia-se a possibilidade de realização do hombre natural, que é facultada a um povo que avance um projeto alternativo em condições de evitar os males associados à modernidade ocidental. Neste ponto, é possível explicitar o alcance e as limitações da chave interpretativa martiana.

\section{Alcance}

A sensível percepção de afinidades do ponto de vista cultural, remetidas a um passado identificado no colonialismo e que se atualizam na semelhança dos dilemas históricos presentes, permite a Martí visualizar a América Latina como uma totalidade.

Dito de outra maneira, a projeção de Nuestra América como desígnio civilizatório está enraizada, em primeira instância, em um conjunto de percepções referenciadas precisamente a uma racionalidade alternativa à ocidental: Nuestra América é antes uma intuição do que uma constatação "lo que es en mí vastísimo sentimiento continental" (MARTÍ, 2000, tomo II, p. 11). Sua premissa é antes subjetiva do que objetiva: é o terreno fértil no qual se verificam as condições históricas e a possibilidade ética — ou seja, o caráter — propício para semear o hombre natural.

Podemos aventar a conjectura avessa: se o ângulo precípuo da abordagem martiana fosse econômico ou político, teria visualizado com semelhante intensidade a unidade latino-americana? Não sugerimos que a projeção de Nuestra América esteja desprovida de lastro objetivo, mas que a chave por meio da qual Martí identifica essa potencialidade é uma matriz cultural comum. 
Do ponto de vista histórico, este ideário está assentado em uma dupla percepção: de um lado, a possibilidade recente de afirmação da identidade americana, uma vez superadas as tendências centrífugas que dificultaram o processo de construção dos estados nacionais durante o século XIX. De outro, o expansionismo estadunidense confronta o continente com o imperativo da unificação que se apresenta como um dilema: ou uma proposta de modernidade alternativa referida à autoctonia, ou a unidade configurada em torno da modalidade de dominação neocolonial que se anuncia.

Assim, o desígnio de Nuestra América está assentado não apenas em afinidades históricas passadas, mas na encruzilhada histórica que se coloca e unifica o destino daqueles que não se reconhecem unidos.

Nessa perspectiva, a positivação da sua especificidade cultural aparece como premissa de uma emancipação das mentalidades, condição para a projeção de uma unidade continental capaz de se contrapor soberanamente no cenário geopolítico mundial.

A disjuntiva é promover a unidade da região em bases soberanas em contraposição ao expansionismo dos Estados Unidos, ou ver seu destino aproximado pela subordinação comum a estes interesses. Dito de outra maneira: afirmar uma posição soberana no concerto geopolítico mundial, alicerçada em um projeto de modernidade alternativa dotada de um conteúdo civilizatório universal, ou servir aos desígnios da disputa geopolítica global como região satélite do poder estadunidense.

\section{LiMites}

Se a chave interpretativa martiana possibilitou a clara percepção da encruzilhada histórica que se avizinhava, foi insuficiente para identificar os seus nexos com a dinâmica do capitalismo. Sintoma evidente é que Martí associa o ódio de classes que observa na Europa e nos Estados Unidos, fenômeno típico e característico do padrão de estratificação social capitalista, ao legado feudal que, no segundo caso, supõe uma espécie de regressão histórica, que cria um novo feudalismo. A citação completa:

[…] cuando se palpó que los inventos más útiles, puestos en ejercicio con abundancia ilimitada en el país más libre de la tierra, reproducen en pocos años la misma penuria, la misma desigualdad, las mismas acumulaciones de riqueza y de odio, los mismos sobresaltos y riesgos que en los pueblos de gobierno despótico o libertad inquieta se han acumulado con el concurso de los siglos; cuando se observó definitivamente que la maravilla de la mecánica, la exuberancia del suelo, la masa de población, la enseñanza pública, la tolerancia religiosa y la libertad política, combinadas en el sistema más amplio y viril imaginado por los hombres, crean un nuevo feudalismo en la tierra y en la industria, con todos los elementos de una guerra social, entonces se vio que la libertad política no basta a hacer a los hombres felices y hay un vicio de esencia en el sistema que con los elementos más favorables de libertad, población, tierra y trabajo, trae a los que viven en él a un estado de odio y desconfianza constante y creciente, y a la vez que permite la acumulación ilimitada en unas cuantas manos de la riqueza de 
carácter público, priva a la mayoría trabajadora de las condiciones de salud, fortuna y sosiego indispensables para sobrellevar la vida. (MARTÍ, 2000, tomo II, p. 76.)

No entanto, Martí não opina que "las costumbres de la República engendran los mismos vicios de las monarquías privilegiadas y ociosas" (MARTÍ, 2000, tomo II, p. 80). Entende Martí que a prática eleitoral faculta aos Estados Unidos possibilidades únicas de reforma pacífica. Este otimismo diminui à medida que Martí agudiza sua crítica à sociedade deste país, assim como reduz o papel da imigração europeia no atiçamento do ódio de classes. Em outras palavras, não estima que a semelhança no padrão de sociabilidade entre os dois é dada, antes de mais nada, pelas relações de produção capitalistas — "América es pues, lo mismo que Europa!" (MARTÍ, 2000, tomo II, p. 190).

O núcleo da sua crítica da sociabilidade é o ódio de classes como padrão do conflito social. Atribui este ódio ao caráter dos povos, que é expressão ética de uma construção histórica: no caso europeu, remete ao despotismo e à monarquia "[ [...] naciones donde la servidumbre rural y las castas de cincuenta siglos han puesto a los hombres en diferencias innecesarias y artificiales en Europa, o diversas y menos graves en América" (MARTÍ, 2000, tomo II, p. 104); nos Estados Unidos trata-se de uma corrupção, em que "el afán exclusivo por la riqueza perverte el carácter" (MARTÍ, 2000, tomo II, p. 78).

Sob esta ótica, a própria noção de "ódio" de classes, se contrastada com "luta" de classes, revela um conteúdo ético, cuja premissa é a crença de que é possível para um povo de caráter distinto afirmar uma sociabilidade alternativa assentada no amor. Dito de outra maneira, a chave para a resolução do conflito social é para Martí antes ética do que econômica, embora as esferas não se apresentem completamente diferenciadas. Isto é viável uma vez que o ponto de partida da crítica martiana é o homem produzido pela sociabilidade capitalista, não as relações de produção que engendram este homem.

A premissa subjacente é que é possível estabelecer um padrão alternativo de sociabilidade que promova formas de reivindicação social que prescindam da violência sem alterar as relações de produção ${ }^{(2)}$. Se não são as relações de produção que determinam a sociabilidade, é facultado a um povo onde convergem condições históricas e possibilidades éticas favoráveis viver de forma alternativa no modo de produção capitalista. Ou seja, há espaço para outra forma de sociabilidade no capitalismo.

Em suma, Martí não estabelece os nexos entre as relações de produção capitalistas e a sua sociabilidade em geral. As relações entre a propriedade privada dos meios de produção, a mercantilização do trabalho e as formas de sociabilidade resultantes escapam à problemática martiana - o problema do fetiche lhe é alheio. Sua percepção do padrão de conflito social é superficial e de matiz ético: concentra-se nas suas formas de expressão, assim como, de maneira correspondente, suas observações econômicas se circunscrevem à esfera da circulação. Em ambos os casos, não adentra o terreno das relações de produção.

Além do fetichismo nas relações sociais, o outro ângulo a partir do qual é possível criticar a propriedade privada do ponto de vista do materialismo histórico é como óbice ao

(2) Observa-se que, inicialmente, Martí preza muito a dinâmica eleitoral dos Estados Unidos. Por exemplo, atribui a radicalidade dos imigrantes alemães à falta de espaço para o embate político legal na Alemanha contemporânea. À medida que se acentua sua crítica à sociedade estadunidense, porém, o cubano também se desilude sobre as virtudes da democracia daquele país e se dá conta do seu alto grau de mercantilização. 
desenvolvimento das forças produtivas. Como a visão de progresso martiana não é alinhavada por este eixo, o resultado é, de um lado, que não se produz uma teleologia, isto é, não há um padrão de desenvolvimento histórico a ser seguido — e de outro, não se encontra em sua obra uma crítica à propriedade privada.

A superação da disjuntiva ideológica civilização ou barbárie é a premissa para uma visão da história centrada na autoctonia e, portanto, avessa a qualquer teleologia: "ni de Rosseau ni de Washington debe surgir nuestra América sino de sí misma." (MARTÍ, 2000, tomo III, p. 280.)

\section{Martí versus Marx}

Uma leitura atenta da nota de Martí a respeito de Karl Marx redigida por ocasião do seu falecimento em 1883 evidencia o contraste entre o pensamento martiano e o materialismo histórico. No conjunto da nota, Martí empatiza com as ideias de Marx, mas não com seus métodos. Esta empatia está calcada na defesa em comum dos trabalhadores: "Como se puso del lado de los débiles, merece honor.” (MARTÍ, 2000, tomo I, p. 403.) Conforme ressalta Almada:

La reflexión de Martí sobre los asuntos económicos de mueve en general en el ámbito de la circulación y en lo que se ha dado en llamar la macroeconomía. La esfera de la producción y el análisis microeconómico están prácticamente ausentes en él. (ALMADA, 1990, p. 437.)

Nesta sentença que abre o comentário, explicita-se a diferença de enfoque em relação aos trabalhadores, que vai determinar o grau de identidade entre ambos pensadores. Se para Marx a classe trabalhadora é protagonista em potencial da revolução mundial que se anuncia, Martí a vê como o lado fraco (débiles) a ser amparado no conflito social. Nesta diferença, radica uma empatia, mas também uma distância: Marx merece ser honrado, o que não significa tomá-lo como referência política ou teórica.

A diferença na abordagem entre os pensadores é explícita em outra passagem: "El trabajo embellece. […] De manejar las fuerzas de la naturaleza, les viene ser hermosos como ellas." (MARTÍ, 2000,tomo I, p. 403.)

A referência do pensador cubano ao enfocar a relação do homem com seu trabalho é a realização do hombre natural, que encontra na relação orgânica com a natureza uma via de contato com o transcendente, onde, para Marx, coloca-se o problema da formação da consciência de classe. "Y el hombre no se halla completo, ni se revela a sí mismo, ni ve lo invisible, sino en su íntima relación con la naturaleza." (MARTÍ, apud BALLÓN, 1995, p. 83.)

Nesta chave, embora concorde com a indignação causada por uma engrenagem de exploração que provoca a desumanização do trabalhador, o cubano critica Marx por promover métodos que, a seu ver, podem levar ao aprofundamento da bestialização que se combate. "Mas se ha de hallar salida a la indignación, de modo que la bestia cese, sin que se desborde, y espante." (MARTÍ, 2000, tomo II, p. 403.) 
Está implícita uma crítica à violência que substancia o ideário revolucionário marxista, assentado na premissa de que as contradições engendradas pelo capitalismo somente podem ser superadas mediante a ação organizada dos trabalhadores, que tem como horizonte histórico outro modo de produção.

Se constatarmos que Martí não é um pacifista por princípio, pois defende a violência revolucionária em que não se apresenta alternativa, como no caso cubano " $[\ldots .$.$] una vez$ agotado el recurso pacífico, el ánimo generoso, donde labra el dolor ajeno como el gusano en la llaga viva, acude al remedio violento (MARTÍ, 2000, tomo II, p. 190)", deduzimos que considera viáveis outros meios de reforma social no capitalismo, que prescindam da violência intrínseca à revolução comunista.

Assim, Martí avalia as derivações políticas do pensamento marxista como apressadas, sombrias, inviáveis e prematuras: "Pero anduvo de prisa, y un tanto en la sombra, sin ver que no nacen viables, ni de seno de pueblo en la historia, ni de seno de mujer en el hogar, los hijos que no han tenido gestación natural y laboriosa." (MARTÍ, 2000, tomo I, p. 402.)

A premissa subjacente é precisamente oposta ao materialismo histórico, que identifica na conjuntura europeia a maturidade das condições da revolução dos trabalhadores. Onde Martí vê uma cesárea prematura, Marx alerta que estourou a bolsa: o capitalismo está prenhe do comunismo, e a violência é a parteira da história.

\section{Martí Versus SOCIALISMo}

O pensador cubano teve oportunidade de aprofundar seu contato com o socialismo depois da nota sobre Marx. Em seu trabalho Lecturas Norteamericanas de José Martí:Emerson y el socialismo contemporáneo (1880-1887), José Ballón analisou o exemplar lido e anotado pelo cubano entre 1884 e 1887 do livro El socialismo contemporáneo de John Rae. Como diz o título, a obra faz um apanhado das teorias e da atividade socialista na Europa e nos Estados Unidos do século XIX, inclusive 70 páginas que, segundo Ballón, "expone de manera completa y sistemática la doctrina de Karl Marx" (BALLÓN, 1995, p. 38). No entanto, esta não é uma das partes anotadas por Martí, que se concentra no capítulo introdutório, no apartado sobre Lassale e no oitavo capítulo intitulado "El socialismo y la cuestión social". Uma análise a partir do material levantado por Ballón permite aprofundar a apreciação que o cubano faz do socialismo contemporâneo, e suas consequências para o projeto nacional do PRC (Partido Revolucionário Cubano).

Houvesse interesse, Martí poderia ter aprofundado seus conhecimentos sobre a obra de Marx:

Ya desde la década del setenta algunos de los trabajos de Marx, incluido El Capital, podían obtenerse en Estados Unidos, y aunque el primer volumen de su obra monumental no apareció en inglés hasta 1887, entre 1876 y 1878 se publicaron resúmenes en ese idioma en The Socialist y el Labor Standard. (ALMADA, 1990, p. 242.)

Martí sublinha diversas passagens que se referem à relação entre socialismo e Estado, o que permite inferir que o pensador cubano estava familiarizado com o problema do Estado, 
embora esteja ausente do seu pensamento político e da sua estratégia revolucionária. Escreve à margem do livro:

Democracia no es el gobierno de una parte del pueblo o una clase del pueblo sobre otra, porque eso es tiranía. Sino el gobierno de tanto el pueblo en equitativa representación y el equilibrio de las clases, de modo que siempre quede (ilegible) parte que la han de representar. (MARTÍ, apud BALLÓN, 1995, p. 2000, p. 41.)

Esta anotação reitera que Martí subordina a dinâmica da luta de classes à noção de equilíbrio do mundo. Do ponto de vista do Estado, escapa-lhe o seu conteúdo de classe. Por exemplo, aponta: "El socialismo no es una teoría sobre la acción del estado sino una teoría de la acción del Estado basada en los derechos del trabajador." (MARTÍ apud BALLÓN, 1995, p. 41.) Mais além, identifica na ação estatal e na propriedade coletiva dos meios de produção um denominador comum ao emaranhado das tendências socialistas contemporâneas, segundo anota em inglês: "the land of the country and all other instruments of production shall be made the joint property of the community, and the conduct of all industrial operations be placed under the direct administration of the State." (MARTÍ apud BALLÓN, 1995, p. 49.)

Este é o ponto central: Martí rechaça o socialismo, que identifica com a propriedade coletiva e a presença estatal, por entender que são princípios que contradizem o desígnio de afirmação da individualidade contido na noção do hombre natural:

En esos planes falta el espacio preciso para el crecimiento irrepresible de la naturaleza humana, que es la base de todo sistema social posible, porque un conjunto de hombres, sólo por transición y descanso puede ser distinto de como el hombre es: lo innatural, aun cuando sea lo perfecto, no vive largo tempo. (MARTÍ, apud ALMADA, 1990, p. 255.)

Ainda: "El principio martiano del valor de la libre actividad creadora del individuo era incompatible con el estatismo y la regulamentación comunitarios [...]." (ALMADA, 1990, p. 226.) Sob esta perspectiva, o socialismo é uma doutrina bem intencionada, mas desnecessariamente violenta e, portanto, excessiva: "De todo eso, por supuesto, sólo se puede considerar el buen deseo, y la verdad de los dolores punzantes que por serlo tanto llevan los planes de reforma a tal exceso [...]." (ALMADA, 1990, p. 226.)

A premissa desta avaliação é que a luta de classes (na linguagem martiana, o ódio de classes) não é constitutiva do capitalismo, mas é uma característica de povos de determinado caráter, diferente daquele que identifica em Nuestra América. Daí sua recusa do socialismo, encarado como um conjunto de doutrinas citadas em última instância, a um problema estrangeiro. Referindo-se ao socialismo cubano, escreve em carta um ano antes de morrer:

Dos peligros tiene la idea socialista, como tantas otras: el de las lecturas extranjerizas, confusas e incompletas, y el de la soberbia y rabia disimulada de los ambiciosos, que para ir levantándose en el mundo empiezan por fingirse, para tener hombros en que alzarse, frenéticos defensores de los desamparados. (MARTÍ, 2000, Tomo III, p. 371.)

Martí finaliza com esta passagem: "[...] el caso es no comprometer la excelsa justicia por los modos equivocados o excesivos de pedirla.” (MARTÍ, 2000, Tomo III, p. 371.) 
Desta forma, Martí recusa as premissas socialistas até o fim, embora simpatize com a sua orientação de classe.

\section{Projeto nacional}

Como resultado, do ângulo do modo de produção, o projeto nacional de Martí não questiona o capitalismo, mas visa criar as condições para uma sociedade mais equilibrada do ponto de vista econômico, com o fim precípuo de promover a realização histórica do hombre natural, alicerçada na autoctonia.

Nesta perspectiva, destacam-se, nas passagens que Martí sublinha no compêndio sobre o socialismo, aquelas que apontam para a construção destas condições o equilíbrio, que se assenta na pequena propriedade, na democracia e no salário justo.

O cubano sublinha, no compêndio de John Rae, passagem em que se mencionam os nexos entre a classe camponesa e a contenção da revolução: "La estabilidad de Europa se puede decir que reside en el número de campesinos acomodados; la contensión de la revolución es la pequeña hacienda." (RAE, 1887, p. 31, sublinhado por Martí.)

De modo análogo, marca a relação entre democracia e o esvaziamento da pressão socialista: "La condición de Suiza muestra de manera suficientemente clara que la democracia bajo un régimen de libertad no presta oído al socialismo, sino que enfila el rostro a direcciones completamente distintas." (RAE, 1887, p. 47, sublinhado por Martí.)

Sua visão de democracia aparece anotada à margem do livro, quando reitera a subordinação da luta de classe à noção de equilíbrio do mundo, o que traz como consequência uma visão do Estado desprovista de conteúdo classista:

Democracia no es el gobierno de una parte del pueblo o una clase del pueblo sobre otra, porque eso es tiranía. Sino el gobierno de tanto el pueblo en equitativa representación y el equilibrio de las clases, de modo que siempre quede (ilegible) parte que la han de representar. (MARTÍ apud BALLÓN, 1995, p. 41.)

Do ponto de vista econômico, anotamos que Martí restringiu suas observações ao campo da circulação, sem incursionar, por exemplo, no problema da mais-valia. O resultado no plano teórico foi a filiação à teoria dos fatores de produção, o que encaminhou a reivindicação dos trabalhadores para o campo salarial. Assim, o cubano sublinha, no compêndio de Rae (1887):

El precio del trabajo está ahora determinado por la lucha entre el trabajador y el empresario, y el resultado de esa lucha se mueve entre dos límites muy reales, aunque no definitivamente marcados: el inferior, que consiste en la cantidad mínima que un obrero puede aceptar, y el superior, que consiste en la cantidad mayor que el empresario pueda otorgar. (RAE, 1887, p. 47, sublinhado por Martí.)

Pequena propriedade rural, democracia e salários justos resumem o programa social de Martí, assentado na premissa política do equilíbrio entre as classes sociais. Este projeto nacional, reformista do ponto de vista do modo de produção (embora, sob nossa ótica, 
inovador no seu horizonte de modernidade) está alicerçado em uma visão da história na qual a dinâmica da luta de classes está subordinada à noção de equilíbrio do mundo; as relações de produção capitalistas estão subordinadas ao caráter de um povo; o desenvolvimento das forças produtivas está subordinado à autoctonia; a economia está subordinada à ética; e a visão de progresso subordinada ao desígnio do hombre natural.

\section{Conclusão}

Em suma, o instrumental que fundamenta a visão de progresso martiana revela-se capaz de captar a especificidade de Nuestra América no contraste com o Ocidente e projetar-lhe um devir alternativo, fundado em uma fina percepção do dilema histórico que se anunciava; mas é insuficiente para diagnosticar suas semelhanças, radicada na generalização de relações de produção em bases capitalistas. Para tanto, seria necessário um repertório de economia política que não coadunava com o ângulo da abordagem histórica martiana, e possivelmente não encontrava lastro na realidade cubana, em que a difusão relativamente incipiente do assalariamento limitava a diferenciação da esfera econômica.

Embora não adote o instrumental do materialismo histórico, Martí interpreta com precisão os desafios enfrentados pela revolução cubana contemporânea. A frustração deste projeto está inscrita nos constrangimentos para a revolução democrática nacional na América Latina sob o imperialismo, entretanto, a amplitude da sua reflexão antecipa um dilema civilizatório que atravessaria o século: seria viável um projeto de modernidade alternativa no capitalismo?

\section{REFERÊNCIAS BibliográficAS}

ALMADA, Rafael. En torno al pensamiento económico de José Martí. La Habana: Editorial de Ciencias Sociales, 1990.

BALLÓN, José. Lecturas Norteamericanas de José Martí: Emerson y el socialismo contemporáneo (1880-1887). Ciudad de México: UNAM, 1995.

EMERSON, José Martí. In: José Ballón. Lecturas Norteamericanas de José Martí: Emerson y el socialismo contemporáneo (1880-1887). Ciudad de México: UNAM, 1995.

MARTÍ, José. Obras escogidas en tres tomos. La Habana: Editorial de Ciencias Sociales, 2000.

MARTÍ, José. Crônica de José Martí publicada no Anuário do Centro de Estudios Martianos, n. 3, 1980, p. 36-43. In: ALMADA, Rafael. En torno al pensamiento económico de José Martí. La Habana: Editorial de Ciencias Sociales, 1990.

RAE, John. Contemporary Socialism. New York: Charles Scribner's Sons, 1887. 